\title{
Humoral and Cellular Sensitivity to Collagen in Type II
}

\section{Collagen-Induced Arthritis in Rats}

\author{
David E. Trentham, Alexander S. Townes, Andrew H. Kang, and \\ JoHN R. DAvid, Veterans Administration Hospital and Department of \\ Medicine and Biochemistry, University of Tennessee Center for the Health \\ Sciences, Memphis, Tennessee 38104, and the Department of Medicine, \\ Harvard Medical School, Robert B. Brigham Hospital, \\ Boston, Massachusetts 02120
}

\begin{abstract}
A B S T R A C T We have recently described a new animal model of arthritis induced by intradermal injection of a distinct type of collagen found in cartilage (type II collagen). Since immunologic sensitivity to collagen could play a role in the pathogenesis of this type II collagen-induced arthritis in rats, the ability of purified types of native collagens to induce cellular and humoral responses was quantified by antigeninduced tritiated thymidine incorporation into lymphocytes by collagen and passive hemagglutination, respectively. Rats injected intradermally with native heterologous or homologous type II collagens in adjuvant developed type-specific cellular as well as humoral reactivity. Types I and III collagens were less immunogenic than was type II. The latter collagen induced brisk cellular and humoral responses that were equivalent whether complete Freund's adjuvant or incomplete Freund's adjuvant were employed. Both responses could be induced by native type II collagens modified by limited pepsin digestion, indicating that they are not attributable to determinants in the telopeptide regions of the molecule. Thus, these studies demonstrate the unique immunogenic as well as arthritogenic properties of the type II collagen molecule and indicate that both result from a helical conformation of its structurally distinct $\alpha$-chains. Further, they suggest that type II collagen may, by humoral or cellular mechanisms, provoke or perpetuate inflammation in other arthritic diseases.
\end{abstract}

A preliminary account of part of this work was presented at the National Scientific Meeting of the American Rheumatism Association, 10-11 December 1976, Miami Beach, Fla., and the Annual Meeting of the Federation of American Societies for Experimental Biology, 1-8 April 1977, Chicago, Ill.

Received for publication 13 June 1977 and in revised form 26 August 1977.

\section{INTRODUCTION}

In the past $8 \mathrm{yr}$, collagen has been found to be distributed in structurally distinct types in various tissues. Types I and III collagens from the dermis and other tissues have genetically different structures: $[\alpha 1(\mathrm{I})]_{2} \alpha 2$ for type I and [ $\alpha 1$ (III) $]_{3}$ for type III (1). Type II collagen is localized to cartilage (2) and possibly the vitreous, retina (3), and cornea (4) of the eye. Biochemical techniques have also been devised which allow these collagens to be solubilized from tissues in a highly purified native state (1). Thus, by use of these collagen preparations, it is now possible to test the hypothesis proposed by Steffen and Timpl (5) that type-specific immunologic responses to collagen may play a role in inciting or perpetuating inflammation occurring in the connective tissue diseases. Humoral reactions to collagen have been demonstrated in patients with rheumatoid arthritis (5-12). By delineating a unique animal model of autoimmunity, type II collagen-induced arthritis in rats (13), we have provided further support for this hypothesis.

As we recently reported (13), heterologous or homologous type II collagen extracted from cartilage and injected intradermally with adjuvant into rats can induce an inflammatory arthritis. Type I or type III collagen prepared from skin or the denatured constituent $\alpha$-chains comprising type II collagen are not arthritogenic. Histologically, the disease induced by type II collagen is a chronic synovitis. An intense mononuclear cell infiltration of the synovium is found. Hypertrophy of this lining appears to secondarily erode articular cartilage and subchondral bone. These characteristics resemble those of rheumatoid arthritis sufficiently to suggest that this may be an appropriate animal model for the human disease (13). Moreover, since the clinical features and incidence of arthritis are 
the same whether complete Freund's adjuvant (CFA) ${ }^{1}$ or incomplete Freund's adjuvant (ICFA) is injected with type II collagen, this arthritis is unique among animal models of experimentally inducible autoimmunity to a tissue component (14).

In this paper we present data that demonstrate that all of these collagens can induce type-specific cellular as well as humoral immunologic responses in rats. The magnitude of both antibody production to type II collagen and antigen-induced tritiated thymidine $\left(\left[{ }^{3} \mathrm{H}\right] \mathrm{TdR}\right)$ incorporation by lymphocytes correlates with the occurrence of arthritis. Moreover, there is a close temporal association between the development of cellular sensitivity to type II collagen and the onset of arthritis. These findings are consistent with the hypothesis that type-specific immunologic hypersensitivity to the cartilage type of collagen may be involved in the etiology of the disease.

\section{METHODS}

Rats. Outbred female Wistar rats (Harlan, Indianapolis, Ind., and Charles River Breeding Laboratories, Wilmington, Mass.) weighing 175-225 g were used.

Collagens. Human types I, II, and III collagens, human and rat $\alpha 1(\mathrm{I}), \alpha 2$, and $\alpha 1$ (II) and human $\alpha 1$ (III) chains, and a crude proteoglycan complex from human cartilage were prepared by methods previously described (13). Human and rat types I and II and human type III molecules were pepsin-modified to enhance solubility. Chick types I and II were prepared as tropocollagens from lathyritic animals. Chick $\alpha$ l (II) chains were also employed. Purity of each preparation was assessed by carboxymethyl cellulose chromatography and amino acid analysis (13). No proteoglycan contamination in any preparation could be detected by uronic acid assay (15). Hydroxyproline analyses (16) were used to determine the concentrations of soluble collagen used for immunizations or coating red cells for hemagglutination studies.

Immunizations. The immunization regimens were outlined in the previous paper (13) and used either CFA (Difco Laboratories, Detroit, Mich.) containing Mycobacteria butyricum $(0.5 \mathrm{mg} / \mathrm{ml}$ ) or ICFA (Difco Laboratories). Control immunizations with the CFA at this dose and injection site failed to induce adjuvant arthritis in 30 rats. When CFA containing $1.0 \mathrm{mg}$ M. tuberculosis per ml oil (CFA H37Ra, Difco Laboratories) was injected into the tail, adjuvant arthritis could be induced (13). Booster doses consisting of collagen without adjuvant were given intraperitoneally on day 21 unless otherwise noted. Antisera were collected by distal tail amputation or cardiac puncture under ether anesthesia $\mathbf{4 2}$ days after primary immunization unless otherwise specified.

Antibody detection. Antibodies were quantified by a passive microhemagglutination technique involving glutaraldehyde fixation of human (blood group $\mathrm{O}, \mathbf{R h}+$ ) erythrocytes sensitized with the collagen preparations $(17,18)$. The final procedure was identical with that of Andriopoulos et al. (11), except that because of varying solubilities of the different collagens determined by hydroxyproline assay, a $5 \%$ suspen-

${ }^{1}$ Abbreviations used in this paper: CFA, complete Freund's adjuvant; $\left[{ }^{3} \mathrm{H}\right] \mathrm{TdR}$, tritiated thymidine; ICFA, incomplete Freund's adjuvant; SI, stimulation index. sion of cells was sensitized by the addition of an equal volume of $0.1 \mathrm{M}$ calcium acetate containing the following collagen concentrations: $0.1 \%$ human types I and III; $0.02 \%$ human, chick, and rat type II; and $0.05 \%$ chick or rat type I or $\alpha$-chains. Higher collagen concentrations tended to cause nonspecific agglutination. Sodium azide, $0.1 \%$, was routinely used as a preservative and $0.1 \%$ bovine serum albumin as a stabilizer. Cells were stored at $4^{\circ} \mathrm{C}$ and used within $2 \mathrm{wk}$ after preparation. Repeat testing of standard antisera showed no fall in titer during this time. Titrations were performed in round-bottom plastic microtiter plates (Cooke Laboratory Products Div., Dynatech Laboratories Inc., Alexandria, Va.) and were compared with control cells not coated with collagen. Mean titers are expressed as serial $-\log _{2}$ dilutions \pm SEM.

Mercaptoethanol reduction. $0.25 \mathrm{ml}$ of antisera from rats receiving only primary immunization were treated with 0.05 $\mathrm{ml}$ of $0.2 \mathrm{M}$ mercaptoethanol in $0.25 \mathrm{M}$ Tris- $\mathrm{HCl}$ buffer, $\mathrm{pH}$ 8.6 , for $1 \mathrm{~h}$ at $37^{\circ} \mathrm{C}(19)$. Immediately after incubation, hemagglutination titers of the treated sera were compared with those of the sera treated with buffer alone.

Peripheral blood mononuclear cell cultures. Cellular sensitivity to collagen was assessed by antigen-induced $\left[{ }^{3} \mathrm{H}\right] \mathrm{TdR}$ incorporation by peripheral blood mononuclear cells. $3-4 \mathrm{ml}$ of blood with heparin were obtained by cardiac puncture under ether anesthesia. Mononuclear cells were isolated by diluting blood 1:2 with Hanks' balanced salt solution (Microbiological Associates, Bethesda, Md.) and layering over FicollHypaque or lymphocyte separation medium (Bionetics Laboratory Products, Kensington, Md.) gradients. After centrifugation, approximately $4-6 \times 10^{6}$ mononuclear cells per original milliliter of blood could be obtained. After two washings in media, cells were counted with a hemocytometer or a Coulter Counter (Coulter Electronics Inc., Hialeah, Fla.). They were then suspended at a concentration of $10^{6} / \mathrm{ml}$ in RPMI 1640 (Microbiological Associates) supplemented with penicillinstreptomycin ( $100 \mathrm{U}$ and $100 \mu \mathrm{g} / \mathrm{ml}$, respectively) made to contain $8 \%$ fresh rat serum. Viability, tested by exclusion of $0.2 \%$ trypan blue, was greater than $95 \%$.

Initially, $1.0-\mathrm{ml}$ aliquots were cultured in triplicate in Falcon 3033 tubes (Falcon Plastics, Division of BioQuest, Oxnard, Calif.) and harvested with a Millipore sampling manifold (Millipore Corp., Bedford, Mass.). Later, cells were cultured in quadruplicate with a microtechnique in sterile disposable round-bottom microtiter plates treated for tissue culture (Cooke), each well containing $2 \times 10^{5}$ cells in $0.2 \mathrm{ml}$ of media. Cells were exposed to $1.0 \mu \mathrm{Ci}$ of $\left[{ }^{3} \mathrm{H}\right] \mathrm{TdR}$ (sp act $6.7 \mathrm{Ci} / \mathrm{mmol}$, New England Nuclear, Boston, Mass.) for the final $16 \mathrm{~h}$ of culture. They were then aspirated onto glass fiber filters with a MASH-II cell harvester (Microbiological Associates) and were flushed successively with distilled water and methanol. After drying, incorporation of label was assessed by scintillation spectrometry and was expressed as mean counts per minute \pm SEM for the triplicate or quadruplicate cultures. Time-response studies showed that incorporation of $\left[{ }^{3} \mathrm{H}\right] \mathrm{TdR}$ induced by mycobacterial antigen or collagen was not enhanced by culturing cells for longer than 4 days. Mitogen responses were maximal in $72-\mathrm{h}$ cultures. Dose-response kinetics indicated that the addition of $20 \mu \mathrm{l}$ phytohemagglutinin (PHA-M, Difco Laboratories), $20 \mu \mathrm{g}$ concanavalin A (Miles-Yeda Laboratory, Elkhart, Ind.), and $100 \mu \mathrm{g}$ of desiccated, heat-killed M. butyricum or M. tuberculosis (Difco Laboratories) per $10^{6}$ cells were optimal. Cultures routinely included mitogen controls and were harvested at 4 days.

Since the incremental addition of acid or salt solutions capable of dissolving collagen linearly ablated phytohemagglutinin responses, enhanced $\left[{ }^{3} \mathrm{H}\right] \mathrm{TdR}$ incorporation by collagen was initially demonstrated by suspension in media or 
phosphate-buffered saline. Optimal reproducibility and assurance of sterility occurred, however, when collagen was dissolved for $24-48 \mathrm{~h}$ at $4^{\circ} \mathrm{C}$ in $0.1 \mathrm{M}$ acetic acid (PHIX Buffer grade, Pierce Chemical Co., Rockford, Ill.), passed through 0.45- $\mu \mathrm{m}$ Millipore filters (Amicon Corp., Scientific Sys. Div., Lexington, Mass.), and lyophilized in the bottom of tissue culture tubes or plates. Gram stains of the media overlying the collagen or mycobacterial antigens revealed no bacteria at the time of harvesting. $100 \mu \mathrm{g}$ and $20-50 \mu \mathrm{g}$ of all collagens produced maximal thymidine uptake for the macro- and micromethods, respectively. Results are expressed as a stimulation index (SI) where $\mathrm{SI}=\left(\mathrm{cpm}\left[{ }^{3} \mathrm{H}\right] \mathrm{TdR}\right.$ incorporated in cultures with mitogen, mycobacteria, or collagen $) /\left(\mathrm{cpm}\left[{ }^{3} \mathrm{H}\right] \mathrm{TdR}\right.$ incorporated in unstimulated cultures).

Statistical analysis. Comparison of mean group data was performed by use of Student's $t$ test.

\section{RESULTS}

Collagen antibody quantitation. As shown in Table I, the 42-day sera of all 86 rats immunized with human, chick, or rat type II collagen showed hemagglutinating antibodies to the sensitizing collagen. The $-\log _{2}$ titers ranged from 5 to $19(1: 32-1: 524,448)$. Similar titers were found whether CFA or ICFA was used. The majority of sera from rats injected with human, chick, or rat type I or human type III collagen demonstrated antibodies to the sensitizing collagen at 42 days. Use of CFA, however, significantly $(P<0.001)$ enhanced antibody production to both type I and type III collagen. CFA was also required for appreciable antibody formation to denatured chick $\alpha \mathrm{l}(\mathrm{II})$ chains. No antibodies to human types I, II, or III collagen, to rat type I or type II collagen, or to rat $\alpha 1$ (I), $\alpha 2$, or $\alpha 1$ (II) chains were found in 20 unimmunized rats. Likewise, no antibodies to human type II collagen were detected

TABLE I

Hemagglutinating Antibody Production to Collagen

\begin{tabular}{|c|c|c|c|}
\hline \multirow[b]{2}{*}{ Immunogen } & \multirow{2}{*}{$\begin{array}{l}\text { Number sera } \\
\text { with antibodies/ } \\
\text { total number } \\
\text { tested }\end{array}$} & \multicolumn{2}{|c|}{ Titer } \\
\hline & & CFA & ICFA \\
\hline Human type II & $52 / 52$ & $8.4 \pm 0.6(31)^{*}$ & $9.4 \pm 0.5(21)$ \\
\hline Chick type II & $14 / 14$ & & $14.3 \pm 1.0$ \\
\hline Rat type II & $20 / 20$ & $9.7 \pm 0.6(10)$ & $10.4 \pm 0.7(10)$ \\
\hline Chick $\alpha \mathrm{l}(\mathrm{II})$ & $10 / 13$ & $7.2 \pm 0.3(10)$ & $\begin{array}{ll}0 & (3)\end{array}$ \\
\hline Human type I & $30 / 38$ & $7.7 \pm 0.7(21)$ & $4.0 \pm 0.9(17)$ \\
\hline Chick type I & $16 / 20$ & $6.2 \pm 0.5(10)$ & $3.0 \pm 0.3(10)$ \\
\hline Rat type I & $17 / 20$ & $5.5 \pm 0.5(10)$ & $2.0 \pm 0.5(10)$ \\
\hline Human type III & $25 / 28$ & $8.3 \pm 0.5(20)$ & $3.5 \pm 1.2(8)$ \\
\hline None & $0 / 20$ & & \\
\hline
\end{tabular}

* Mean \pm SEM $-\log _{2}$ antibody titers to the collagen used for sensitization in 42-day sera from rats receiving primary intradermal injection of solubilized collagen with the specified adjuvant and 21-day i.p. booster doses of the collagen alone. Number in parentheses quantitates antisera tested. Sera from 20 unimmunized rats did not contain antibodies to human or rat collagens. in sera from 10 rats injected with this collagen without adjuvant or in 5 rats injected with the crude proteoglycan complex from human cartilage emulsified in CFA.

Antisera to type II treated with mercaptoethanol. Human type II antisera collected on day 15 (mean titer $7.8 \pm 0.5$ ), day 21 (mean $6.5 \pm 0.3$ ), and day 42 (mean $12.2 \pm 0.8$ ) in 4 arthritic rats each and 42-day antisera from 4 nonarthritic rats (mean $7.5 \pm 0.6$ ) were subjected to mercaptoethanol reduction. None had received 21day booster doses of collagen. A mean $-\log _{2}$ titer fall of $5.0 \pm 0.6,3.5 \pm 0.6,2.7 \pm 0.3$, and $1.0 \pm 0.4$ occurred in the four groups, respectively. This indicates a progressive rise of mercaptoethanol-resistant antibodies (IgG) with length of time after immunization.

Cellular sensitivity to collagen. Studies on antigeninduced $\left[{ }^{3} \mathrm{H}\right] \mathrm{TdR}$ incorporation into lymphocytes demonstrate that these collagens can also elicit cellular sensitivities in rats. Peripheral blood mononuclear cells from 10 unimmunized Wistar rats did not exhibit enhanced $\left[{ }^{3} \mathrm{H}\right] \mathrm{TdR}$ incorporation when cultured with human types I, II, and III collagens. Table II quantitates $\left[{ }^{3} \mathrm{H}\right] \mathrm{TdR}$ incorporation, expressed as an SI, by peripheral blood mononuclear cells obtained from Wistar rats injected 42-70 days earlier with collagen in CFA or ICFA and cultured with the collagen used for sensitization. Cells from 29 of 37 rats injected with human, chick, or rat type II collagen had SI $\geqslant 2$ when exposed in vitro to these collagens (mean SI 6.3 \pm 1.4 ). Equivalent $\left[{ }^{3} \mathrm{H}\right] \mathrm{TdR}$ incorporation was found in vitro regardless of whether CFA or ICFA had been injected into the rats with type II collagen (mean SI $5.2 \pm 1.4$ for 18 rats injected with type II in CFA, mean $7.2 \pm 2.5$ for 19 rats injected with type II in ICFA, $P$ not significant). Likewise, incorporation induced by sensitization with homologous or heterologous type II collagen was also similar (mean SI 3.1 \pm 0.4 for 7 rats injected with rat type II, mean $7.0 \pm 1.8$ for 30 rats injected with human or chick type II, $P$ not significant). Finally, the magnitude of incorporation induced by the specific species of heterologous type II collagen used for sensitization was similar in rats injected with human (pepsin-modified) or chick (tropocollagen) type II collagen (mean SI 6.3 \pm 1.9 for 24 rats injected with human type II vs. 9.5 \pm 5.0 for 6 rats injected with chick type II, $P$ not significant). Thus, the cellular response to type II collagen was not attributable to the telopeptide portions of the molecule.

Lymphocytes from some rats injected with human types I and III collagens or chick $\alpha 1$ (II) chains in CFA also showed in vitro sensitivity to these respective collagens (Table II). Cells from 5 of 9 rats injected with type I and 4 of 8 rats with type III, both in CFA, exhibited enhanced $\left[{ }^{3} \mathrm{H}\right] \mathrm{TdR}$ incorporation $(\mathrm{SI} \geqslant 2)$ to their sensitizing collagen (mean SI $3.0 \pm 0.8$ and 3.0 \pm 0.9 , respectively) when tested $42-70$ days later. SI $\geqslant 2$ were found in cells from 3 of 10 rats injected with $\alpha 1$ (II) chains in CFA (mean SI $1.3 \pm 0.3$ ). In contrast to 
TABLE II

$\left[{ }^{3} \mathrm{H}\right] \mathrm{TdR}$ Incorporation by Cells to Their Sensitizing Collagen

\begin{tabular}{|c|c|c|c|c|}
\hline & $\begin{array}{c}\text { Human } \\
\text { type I }\end{array}$ & $\begin{array}{c}\text { Human, chick, or rat } \\
\text { type II }\end{array}$ & $\begin{array}{l}\text { Human } \\
\text { type III }\end{array}$ & $\begin{array}{l}\text { Chick } \alpha 1(\text { II }) \\
\quad \text { chains }\end{array}$ \\
\hline & $\begin{array}{l}8.4(76 \pm 13)^{*} \\
5.0(169 \pm 29) \\
3.1(97 \pm 32) \\
2.3(125 \pm 18) \\
2.1(256 \pm 56) \\
1.9(181 \pm 69) \\
1.7(255 \pm 62) \\
1.5(218 \pm 17) \\
1.3(312 \pm 39) \ddagger \\
1.2(280 \pm 21) \ddagger \\
1.0(222 \pm 19) \ddagger \\
1.0(269 \pm 36) \ddagger \\
0.8(220 \pm 26) \ddagger \\
0.7(546 \pm 43)\end{array}$ & $\begin{array}{ll}41.2 \ddagger & (135 \pm 17) \\
32.0 \ddagger \S & (54 \pm 5) \\
26.0 & (47 \pm 4) \\
15.2 \ddagger \S & (95 \pm 12) \\
11.8 & (136 \pm 33) \\
7.9 \ddagger & (169 \pm 23) \\
7.8 & (196 \pm 59) \\
7.1 & (102 \pm 8) \\
6.8 & (419 \pm 52) \\
5.7 & (382 \pm 79) \\
5.1 & (737 \pm 78) \\
4.7 \ddagger " & (529 \pm 29) \\
4.5 & (257 \pm 46) \\
4.5 \ddagger \S & (152 \pm 40) \\
3.8 \ddagger^{\prime \prime} & (1626 \pm 133) \\
3.7 \ddagger " & (224 \pm 21) \\
3.7 \ddagger \S & (143 \pm 25) \\
3.2 \ddagger & (158 \pm 53) \\
3.2 & (108 \pm 17) \\
3.0 & (573 \pm 63) \\
3.0 \ddagger \text { (1) } & (1363 \pm 52) \\
2.5 & (344 \pm 64) \\
2.4 & (124 \pm 9) \\
2.4 \ddagger " & (840 \pm 83) \\
2.3 \ddagger " & (478 \pm 46) \\
2.3 \ddagger & (358 \pm 57) \\
2.0 \ddagger & (76 \pm 6) \\
2.0 \ddagger & (107 \pm 38) \\
2.0 & (139 \pm 7) \\
1.8 & (71 \pm 5) \\
1.7 \ddagger " & (525 \pm 55) \\
1.3 & (398 \pm 14) \\
1.1 \ddagger \S & (186 \pm 5) \\
1.0 & (541 \pm 69) \\
1.0 & (378 \pm 97) \\
0.6 & (1098 \pm 139) \\
0.5 \ddagger \S & (146 \pm 28)\end{array}$ & $\begin{array}{l}9.0(192 \pm 49) \\
3.5(446 \pm 115) \\
2.8(418 \pm 109) \\
2.2(514 \pm 149) \\
1.9(681 \pm 12) \\
1.9(578 \pm 6) \\
1.6(327 \pm 22) \\
1.3(226 \pm 18) \ddagger \\
1.1(210 \pm 26) \ddagger \\
1.0(398 \pm 19) \\
0.8(192 \pm 8) \ddagger \\
0.8(242 \pm 14) \ddagger \\
0.5(268 \pm 30) \ddagger\end{array}$ & $\begin{array}{ll}2.8 & (393 \pm 45) \\
2.7 & (432 \pm 22) \\
2.1 & (605 \pm 77) \\
1.7 & (362 \pm 63) \\
1.6 & (374 \pm 46) \\
1.2 & (362 \pm 30) \downarrow \\
1.0 & (288 \pm 32) \downarrow \\
0.8 & (328 \pm 16) \ddagger \\
0.8 & (186 \pm 10) \ddagger \\
0.7 & (961 \pm 354) \\
0.6 & (655 \pm 197) \\
0.6 & (138 \pm 55) \\
0.3(1270 \pm 351) \\
0.2(1023 \pm 203)\end{array}$ \\
\hline $\begin{array}{l}\text { Mean CFA } \\
\text { ICFA }\end{array}$ & $\begin{array}{l}3.0 \pm 0.8(214 \pm 47) \\
1.1 \pm 0.1(261 \pm 18)\end{array}$ & $\begin{array}{l}5.2 \pm 1.4(333 \pm 65) \\
7.2 \pm 2.5(391 \pm 101)\end{array}$ & $\begin{array}{l}3.0 \pm 0.9(444 \pm 53) \\
0.9 \pm 0.1(228 \pm 13)\end{array}$ & $\begin{array}{l}1.3 \pm 0.3(621 \pm 113) \\
1.0 \pm 0.1(291 \pm 38)\end{array}$ \\
\hline Total & $2.3 \pm 0.6(230 \pm 31)$ & $6.3 \pm 1.4(362 \pm 60)$ & $2.2 \pm 0.6(361 \pm 44)$ & $1.2 \pm 0.2(527 \pm 90)$ \\
\hline
\end{tabular}

* Mean $\left[{ }^{3} \mathrm{H}\right] \mathrm{TdR}$ incorporation, expressed as a SI, by peripheral blood lymphocytes obtained from rats 42-70 days after primary immunization and cultured in triplicate or quadruplicate with the collagen used for sensitization. Parentheses enclose mean background cpm \pm SEM.

$\ddagger$ ICFA employed, all other rats sensitized with CFA at a dose which alone did not induce adjuvant arthritis.

\$Cultures from rats sensitized and tested with chick type II collagen.

"Immunogen and test antigen rat type II collagen. Remainder of type II collagen-tested rats involved human collagen.

the cellular sensitization achieved to type II collagen with use of ICFA, cells from rats injected with human type I or type III or chick $\alpha 1$ (II) chains failed to respond in vitro to these collagens (Table II).
Specificities of collagen-induced $\left[{ }^{3} \mathrm{H}\right] T d R$ incorporation by cells. Table III quantitates the helical, species, and collagen type-specificities of the cellular response to collagen. Optimal incorporation of $\left[{ }^{3} \mathrm{H}\right]$ 
TABLE III

Specificity of $\left[{ }^{3} \mathrm{H}\right] \mathrm{TdR}$ Incorporation by Lymphocytes to Collagen

\begin{tabular}{lcccr}
\hline & \multicolumn{4}{c}{ Rats sensitized to } \\
\cline { 2 - 5 } \multicolumn{1}{c}{$\begin{array}{l}\text { Lymphocytes } \\
\text { cultured with }\end{array}$} & $\begin{array}{c}\text { Human } \\
\text { type I }\end{array}$ & $\begin{array}{c}\text { Human } \\
\text { type II }\end{array}$ & $\begin{array}{c}\text { Chick } \\
\text { type II }\end{array}$ & $\begin{array}{c}\text { Human } \\
\text { type III }\end{array}$ \\
\hline Human type I & $5.2 \pm 1.8(3)^{*}$ & $1.8 \pm 0.4(13)$ & & $1.2 \pm 0.4(2)$ \\
Human type II & $1.0 \pm 0.4(2)$ & $5.6 \pm 1.7(14)$ & & $1.4 \quad(1)$ \\
Human type III & $2.0 \pm 0.7(3)$ & $1.8 \pm 0.5(14)$ & & $5.6 \pm 3.4(2)$ \\
Chick type I & & & $1.4 \pm 0.2(4)$ & \\
Chick type II & & & & \\
Human type II & & $9.9 \pm 5.6(7)$ & & \\
Human $\alpha 1($ II) chains & & $2.2 \pm 0.8(7)$ & & \\
Rat type II & & $3.1 \pm 1.0(7)$ & & \\
Chick type II & & $0.9 \pm 0.2(7)$ & & \\
\hline
\end{tabular}

$*\left[{ }^{3} \mathrm{H}\right] \mathrm{TdR}$ incorporation by lymphocytes exposed in vitro to collagen expressed as mean $\mathrm{SI} \pm \mathrm{SEM}$ for triplicate or quadruplicate cultures. Parentheses enclose number of rats from which lymphocytes were tested.

TdR by cells required culturing with collagen of the same type and species used for sensitization. Moreover, cells sensitized to native human type II collagen responded poorly when cultured with denatured human $\alpha 1$ (II) chains. This signifies cellular recognition of helical antigenic determinants.

Comparison of sensitivity to collagen in arthritic vs. nonarthritic type II collagen-injected rats. Although the 42-day sera from both arthritic and nonarthritic rats immunized with type II collagen contained antibodies to these collagens, titers were significantly higher in sera from arthritic rats. This was true for rats injected with human type II collagen (mean $-\log _{2}$ titer 10.9 \pm 0.6 for 17 arthritic rats vs. $7.9 \pm 0.4$ for 35 nonarthritic rats, $P<0.0001$ ) or with chick type II collagen (mean $16.4 \pm 0.4$ for 9 arthritic rats vs. $9.8 \pm 1.9$ for 4 nonarthritic rats, $P<0.001)$. The mean $\left[{ }^{3} \mathrm{H}\right] \mathrm{TdR}$ incorporation to type II was also significantly higher in cells from arthritic compared with nonarthritic rats injected 42-70 days earlier with either heterologous or homologous type II collagen (SI $8.7 \pm 2.4$ for 21 arthritic rats vs. 3.0 \pm 0.8 for 16 nonarthritic rats, $P<0.05$ ). However, cells from 8 of the 16 nonarthritic rats did respond in vitro to type II collagen with $S I \geqslant 2$.

Time-course studies. We next assessed whether the onset of humoral or cellular sensitivity to type II collagen was temporally related to the development of arthritis. As shown in Fig. 1 and Table IV, 22 Wistar rats were studied on the day of onset of clinically recognizable arthritis which developed 14-22 days (mean $18 \pm 0.6$ ) after injection of human type II collagen in CFA. 22 rats which remained nonarthritic during the usual time of onset of disease were studied as controls 21-24 days postinjection. $\left[{ }^{3} \mathrm{H}\right] \mathrm{TdR}$ incorporation by unstimulated lymphocytes did not differ significantly in either group (mean $914 \pm 130 \mathrm{cpm}$ arthritic rats vs.
$1,124 \pm 301$ nonarthritic rats). Peripheral blood mononuclear cells from arthritic rats yielded a higher mean SI when cultured with type II collagen than cells from nonarthritic rats $(6.1 \pm 1.6$ vs. $1.1 \pm 0.1, P<0.004)$. Higher mean $-\log _{2}$ antibody titers were also observed in arthritic rats $(8.5 \pm 0.3$ vs. $4.3 \pm 0.6, P<0.0001)$. Fig. 1 illustrates that all arthritic rats had antibodies to type II, and SI was $\geqslant 2$ in all but one. Although $73 \%$ of nonar-

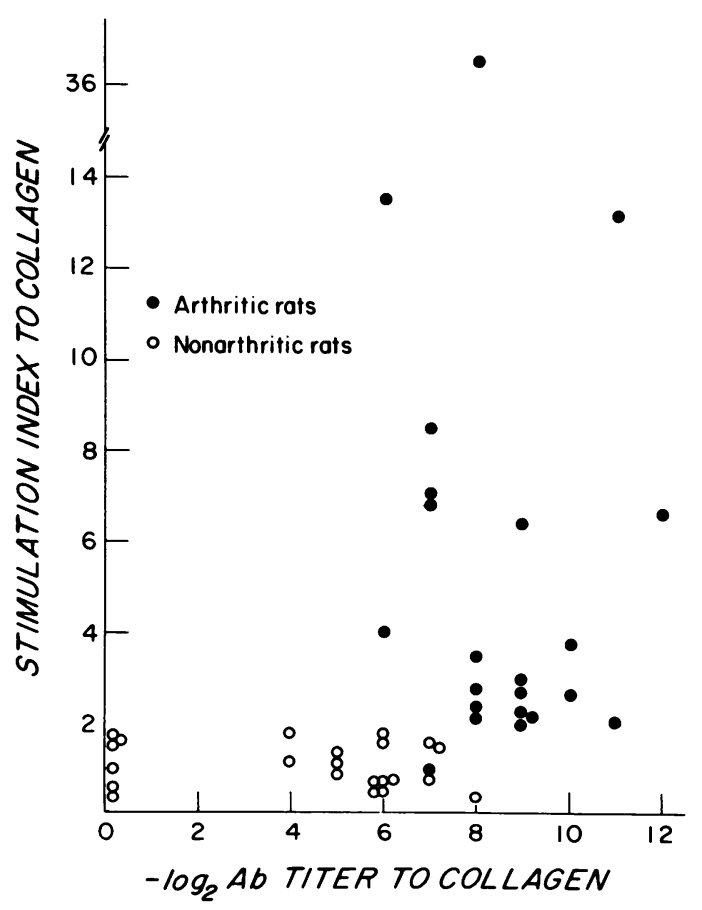

FIGURE 1 Comparison of $-\log _{2}$ antibody titer and SI to type II collagen on the day of onset of collagen-induced arthritis vs. control rats remaining nonarthritic after injection with type II collagen. 
TABLE IV

Time-Course Studies Relating the Development of Immunologic Sensitivity to Type II Collagen with the Onset of Collagen-Induced Arthritis

\begin{tabular}{lcccccc}
\hline & $\begin{array}{c}-\log _{2} \\
\text { ab titer } \\
\text { to type II }\end{array}$ & $\begin{array}{c}\text { Background } \\
\text { cpm }\end{array}$ & PHA & Con A* & M. but & Type II \\
\cline { 5 - 7 } & & & & & & \\
\hline $\begin{array}{c}\text { Arthritic rats } \\
\text { Mean }\end{array}$ & $8.5 \pm 0.3$ & $914 \pm 130$ & $131 \pm 27$ & $241 \pm 50$ & $11.8 \pm 4.2$ & $6.1 \pm 1.6$ \\
$\begin{array}{l}\text { Nonarthritic rats } \\
\text { Mean }\end{array}$ & $4.3 \pm 0.6$ & $1124 \pm 301$ & $50 \pm 20$ & $106 \pm 40$ & $9.4 \pm 6.3$ & $1.1 \pm 0.1$ \\
$P$ value & $<0.0001$ & NS\$ & NS & NS & NS & $<0.004$ \\
\hline
\end{tabular}

Studies of the antibody titers and magnitude of $\left[{ }^{3} \mathrm{H}\right] \mathrm{TdR}$ incorporation by lymphocytes to human type II collagen on the day of onset of arthritis in rats injected with this collagen in CFA compared with these responses in rats remaining clinically nonarthritic 21-24 days after immunization. Both the mean humoral and cellular response to collagen was significantly greater in the arthritic group.

* Concanavalin A.

\$ Desiccated, heat-killed Mycobacteria butyricum present in the CFA used for collagen sensitization and suspended in media for testing as an independent antigen.

$\S$ Not significant.

thritic rats had antibodies to type II, none had SI $\geqslant 2$. Additional studies demonstrated that antibodies to type II collagen were first detected 7 days and lymphocyte proliferation 11 days after immunization.

A similar association of the onset of cellular sensitivity to collagen with arthritis was found when ICFA was injected with chick type II collagen into 12 rats. Lymphocytes obtained on the day of onset of arthritis in 5 rats yielded a higher mean SI to type II than cells from the 7 who remained nonarthritic when studied on days $22-24(2.9 \pm 0.6$ vs. $1.3 \pm 0.1, P<0.01)$. The mean background counts per minute were similar in the two groups $(673 \pm 128$ arthritic vs. $571 \pm 74$ nonarthritic). Higher mean $-\log _{2}$ antibody titers were also found in arthritic rats $(8.4 \pm 0.5$ vs. $6.7 \pm 0.3, P<0.01)$. All 12 rats had antibodies to type II collagen, but cells from only the 5 arthritic rats had SI $\geqslant 2$ to the antigen. Thus, studies employing both CFA and ICFA injected with heterologous type II collagen suggested a temporal association between the development of cellular sensitivity to collagen and the onset of type II collagen-induced arthritis. It should be stressed, however, that our earlier studies had shown that cellular sensitivity to type II collagen was not invariably associated with clinically evident arthritis.

\section{DISCUSSION}

Early studies of the antigenic determinants on native collagen utilized rabbit antisera to heterologous type I and indicated that determinants were primarily located in the nonhelical telopeptide regions of the molecule (20-22). Later work, however, showed that the humoral response to heterologous native type I collagen in rats
$(18,23,24)$ and mice $(25)$ is restricted to helical determinants, since appreciable cross-reactivity of the antisera with the constituent $\alpha$-chains was not observed. Recent evidence demonstrates type-specificity for hemagglutinating antibodies elicited by injection of native heterologous types I and II collagens in CFA $(24,25)$. This again is dependent on a helical conformation of the proteins. Humoral responsiveness to type I and type II bovine collagen differed in several inbred mouse strains, suggesting separate genetic control of antibody production to these different immunogens $(25,26)$.

Cellular sensitization to collagen has previously been reported only in guinea pigs injected with type I collagen and CFA (27-32). Either heterologous (2831 ) or homologous (32) type I collagens in the native (29) or denatured (30) state could induce a cellular response. Guinea pigs injected with native type I collagen showed appreciable skin test reactivities and migration inhibitory factor production when challenged with either the native or denatured protein $(29,32)$. This cross-reactivity and the ability of denatured collagen to induce cellular sensitivity indicate that helical determinants were not involved in eliciting these responses. Extensive cross-reactivities were also found between mammalian skin collagens $(28-30)$. Use of CFA appeared to be essential to elicit cellular sensitivities $(29,32)$. In fact, an initial injection of heterologous type I collagen emulsified in ICFA specifically suppressed the later induction of cellular sensitivity to type I collagen when CFA was used (33). Additional work indicated that the humoral response induced by the initial injection did not appear to function in the suppression of cellular sensitivity $(33,34)$. 
Our results demonstrate for the first time the capacity of the structurally different types of native collagen to provoke cellular sensitivities in rats. Further, in contrast to previous findings in guinea pigs with type I collagens, the responses are specific for the species, type, and native state of the collagen used for sensitization. Pepsin digestion, which cleaves the telopeptide regions of the molecule, does not alter the specificity of the cellular reactivity. This further indicates that both humoral and cellular responses result from determinants located in the rigid triple-helical portion of the native collagens. The unique $\alpha$-chains of each type of collagen, when arranged in a helical conformation, probably function as quarternary determinants and may explain the immunologic discrimination between these polymorphic collagens. Whether the determinants responsible for the humoral and cellular responses to collagens are identical is unknown.

Our studies indicating the helical specificities of the cellular response to collagen may appear to be discrepant from earlier work (27-32). However, a number of differences make it difficult to compare our results with those of previous investigators. These include the use of guinea pigs and only type I collagen in the earlier studies. It would be of interest, therefore, to examine the cellular response in guinea pigs to type II and III collagens and to reevaluate the helical specificity of the response to type I collagen.

Our results also demonstrate that type II collagen as distinct from other types of collagen has unusual immunogenic properties for a protein. Native heterologous or homologous type II collagin consistently induced high antibody titers and cellular sensitivity in rats regardless of whether CFA or ICFA is used. This suggests that type II collagen may have an adjuvant effect for immunologic responses. Moreover, the ability of homologous type II collagen to provoke these responses when emulsified in ICFA demonstrates that it can function in a unique manner for a tissue autoantigen, since other tissue components require CFA to regularly induce such responses (14).

The mechanism by which arthritis is produced by type II collagen injection is not known, although preliminary evidence presented here supports the hypothesis that immunologic hypersensitivity may be involved. The specificity of the immune response to type II collagen parallels its unique arthritogenicity. We have recently achieved adoptive transfer of type II collagen-induced arthritis by sensitized spleen and lymph node cells, more directly implicating immunologic hypersensitivity to type II collagen in the pathogenesis of the disease. ${ }^{2}$ Further, we have recently demonstrated

${ }^{2}$ D. E. Trentham, R. A. Dynesius, and J. R. David. Passive transfer of type II collagen-induced arthritis by cells. Submitted for publication. that cellular (35) and humoral (D. E. Trentham and J. R. David, unpublished data) sensitivities to homologous collagens are present in rats with adjuvant-induced arthritis. Thus, these studies suggest that immunologic sensitivity to the cartilage type of collagen could be involved in provoking, potentiating, or perpetuating joint inflammation in other arthritic diseases.

\section{ACKNOWLEDGMENTS}

We thank Ms. Margaret Cirtin, Ms. Roselynn Dynesius, and Ms. Donna Rowland for their excellent technical assistance.

This study was partially conducted under the Medical Research Service of the Veterans Administration and was supported in part by U.S. Public Health Service grants AM-05055, AI-07685, and AM-05076.

\section{REFERENCES}

1. Seyer, J. M., E. T. Hutcheson, and A. H. Kang. 1977. Collagen polymorphism in normal and cirrhotic human liver. J. Clin. Invest. 59: 241-248.

2. Miller, E. J. 1971. Isolation and characterization of the CNBr-peptides from $\alpha$ l(II) chains of chick cartilage collagen. Biochemistry. 10: 3030-3035.

3. Smith, G. N., T. F. Linsenmayer, and D. A. Newsome. 1976. Synthesis of type II collagen in vitro by embryonic chick neural retina tissue. Proc. Natl. Acad. Sci. U. S. A. 73: 4420-4423.

4. Linsenmayer, T. F., G. N. Smith, and E. D. Hay. 1977. Synthesis of two collagen types by embryonic chick corneal epithelium in vitro. Proc. Natl. Acad. Sci. U. S. A. 74: $39-43$.

5. Steffen, C., and R. Timpl. 1963. Antigenicity of collagen and its application in the serological investigation of rheumatoid arthritis sera. Int. Arch. Allergy Appl. Immunol. 22: 333-349.

6. Steffen, C., F. Schuster, G. Tausch, R. Timpl, and I. Pecker. 1968. Weitere Untersuchungen über Kollagenantikörper bei Patienten mit primär chronischer Polyarthritis. Klin. Wochenschr. 46: 976-981.

7. Steffen, C. 1970. Consideration of the pathogenesis of rheumatoid arthritis as collagen autoimmunity. Z. Immunitätsforsch. 139: 219-227.

8. Michaeli, D., and H. H. Fudenberg. 1974. The incidence and antigenic specificity of antibodies against denatured human collagen in rheumatoid arthritis. Clin. Immunol. Immunopathol. 2: 153-159.

9. Cracchiolo, A., D. Michaeli, L. S. Goldberg, and H. H. Fudenberg. 1975. The occurrence of antibodies to collagen in synovial fluids. Clin. Immunol. Immunopathol. 3: 567-574.

10. Andriopoulos, N. A., J. C. Bennett, J. Mestecky, and E. J. Miller. 1975. The occurrence of antibodies against native human collagens in synovial fluids of patients with rheumatoid arthritis. Arthritis Rheum. 18: 384. (Abstr.)

11. Andriopoulos, N. A., J. Mestecky, E. J. Miller, and E. L. Bradley. 1976. Antibodies to native and denatured collagens in sera of patients with rheumatoid arthritis. Arthritis Rheum. 19: 613-617.

12. Andriopoulos, N. A., J. Mestecky, G. P. Wright, and E. J. Miller. 1976. Characterization of antibodies to the native human collagens and to their component $\alpha$ chains in the sera and the joint fluids of patients with rheumatoid arthritis. Immunochemistry. 13: 709-712.

13. Trentham, D. E., A. S. Townes, and A. H. Kang. 1977. 
Autoimmunity to type II collagen: an experimental model of arthritis. J. Exp. Med. 146: 857-868.

14. Rose, N. R. 1973. Self-recognition and autoimmunity. In Principles of Immunology. N. R. Rose, F. Milgrom, and C. J. van Oss, editors. The Macmillan Company, New York. 217-228.

15. Bitter, T., and H. M. Muir. 1962. A modified uronic acid carbazole reaction. Anal. Biochem. 4: 330-334.

16. Bergman, I., and R. Loxley. 1963. Two improved simplified methods for the spectrophotometric determination of hydroxyproline. Anal. Chem. 35: 1961-1965.

17. Avrameas, S., B. Taudou, and S. Chuilon. 1969. Glutaraldehyde, cyanuric chloride and tetrazotized O-dianisidine as coupling reagents in the passive hemagglutination test. Immunochemistry. 6: 67-76.

18. Beil, W., R. Timpl, and H. Furthmayr. 1973. Conformation dependence of antigenic determinants on the collagen molecule. Immunology. 24: 13-24.

19. Winfield, J. B., D. Koffer, and H. G. Kunkel. 1975. Development of antibodies to ribonucleoprotein following short-term therapy with procainamide. Arthritis Rheum. 18: $531-534$.

20. Schmitt, F. O., L. Levine, M. P. Drake, A. L. Rubin, D. Pfahl, and P. F. Davidson. 1964. The antigenicity of tropocollagen. Proc. Natl. Acad. Sci. U. S. A. 51: 493-497.

21. Michaeli, D., G. R. Martin, J. Kettman, E. Benjamini, D. Y. K. Leung, and B. A. Blatt. 1969. Localization of antigenic determinants in the polypeptide chains of collagen. Science (Wash. D.C.). 166: 1522-1524.

22. Lindsley, H., M. Mannik, and P. Bornstein. 1971. The distribution of antigenic determinants in rat skin collagen. J. Exp. Med. 133: 1309-1324.

23. Hahn, E., and R. Timpl. 1973. Involvement of more than a single polypeptide chain in the helical antigenic determinants of collagen. Eur. J. Immunol. 3: 442-446.

24. Hahn, E., R. Timpl, and E. J. Miller. 1974. The production of specific antibodies to native collagens with the chain compositions, $[\alpha 1(\mathrm{I})]_{3},[\alpha 1(\mathrm{II})]_{3}$, and $[\alpha 1(\mathrm{I})]_{2} \alpha 2 . \mathrm{J} . \mathrm{Im}-$ munol. 13: 421-423.

25. Nowack, H., E. Hahn, and R. Timpl. 1975. Specificity of the antibody response in inbred mice to bovine type $I$ and type II collagen. Immunology. 29:621-628.
26. Hahn, E., H. Nowack, D. Götze, and R. Timpl. 1975. H-2linked genetic control of antibody response to soluble calf skin collagen in mice. Eur. J. Immunol. 5: 288-291.

27. Furthmayr, H., and R. Timpl. 1976. Immunochemistry of collagens and procollagens. Int. Rev. Connect. Tissue Res. 7: 61-99.

28. Michaeli, D., G. Senyk, A. Maoz, and S. Fuchs. 1972. Ascaris cuticle collagen and mammalian collagens: cell mediated and humoral immunity relationships. J. Immunol. 109: 103-109.

29. Adelmann, B. C., J. A. Kirrane, and L. E. Glynn. 1972. The structural basis of cell-mediated immunological reactions of collagen: characteristics of cutaneous delayed hypersensitivity reactions in specifically sensitized guinea pigs. Immunology. 23: 723-738.

30. Adelmann, B. C. 1972. The structural basis of cell-mediated immunological reactions of collagen: reactivity of separated $\alpha$ chains of calf and rat collagen in cutaneous delayed hypersensitivity reactions. Immunology. 23: 739-748.

31. Adelmann, B. C., and J. Kirrane. 1973. The structural basis of cell-mediated immunological reactions of collagen: the species specificity of the cutaneous delayed hypersensitivity reaction. Immunology. 25: 123-130.

32. Senyk, G., and D. Michaeli. 1973. Induction of cell-mediated immunity and tolerance to homologous collagen in guinea pigs: demonstration of antigen-reactive cells for a self-antigen. J. Immunol. 111: 1381-1388.

33. Gentner, G. J., and B. C. Adelmann. 1976. Specific suppression of delayed hypersensitivity skin reactions to collagen in guinea pigs after immunization with collagen and Freund's incomplete adjuvant. Immunology. 31: 8794.

34. Gentner, G. J., and B. C. Adelmann. 1976. The relation between the cell-mediated immunological response and the induction of circulating antibodies to collagen in guinea pigs: investigation of cell functions. Immunology. 31: $95-100$.

35. Trentham, D. E., and J. R. David. 1977. Cellular sensitivity to collagen in adjuvant arthritis. Clin. Res. 25: 369. (Abstr.) 